\section{EDUCAÇÃO FÍSICA E MÍDIA: ESTUDO BIBLIOMÉTRICO NA WEB OF SCIENCE DE 1945-2019}

PHYSICAL EDUCATION AND THE MEDIA: BIBLIOMETRIC STUDY ON

WEB OF SCIENCE - 1945-2019 C

EDUCACIÓN FÍSICA Y MEDIOS DE COMUNICACIÓN: ESTUDIO

BIBLIOMÉTRICO EN LA WEB OF SCIENCE DE 1945 A 2019 C

doi' https://doi.org/10.22456/1982-8918.102377

(iD) Cássia Marques Cândido* <cmarquescandido@yahoo.com.br>

(D) Maxwel de Azevedo Ferreira** <maxwel.ferreira@ifrj.edu.br>

iD Alexandre Palma de Oliveira*** <palma_alexandre@yahoo.com.br>

Monique Ribeiro de Assis* <monique_assis@uol.com.br>

\footnotetext{
*Universidade do Estado do Rio de Janeiro. Rio de Janeiro, RJ, Brasil.

**Instituto Federal de Educação, Ciência e Tecnologia do Rio de Janeiro. Campus

Avançado Resende. Resende, RJ, Brasil.

***Universidade Federal do Rio de Janeiro. Rio de Janeiro, RJ, Brasil.
}

Recebido em: 27 abr. 2020 Aprovado em: 05 fev. 2021 Publicado em: 15 abr. 2021

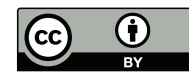

Este é um artigo publicado sob a licença Creative Commons Atribuição 4.0 Internacional (CC BY 4.0).

elSSN: $1982-8918$ 


\section{INTRODUÇÃO}

Ainda que de maneira desigual, a mídia está cada vez mais presente no cotidiano das pessoas, inclusive atualmente sua utilização para fins educacionais tem sido alargada para tornar as aulas possíveis. Isto se deve à suspensão das atividades presenciais em escolas de diferentes localidades do Brasil e do mundo como estratégia preventiva em relação à Covid-19. Neste contexto, muitos desafios são compartilhados pelas variadas disciplinas, porém, dadas as especificidades, cada área se depara com obstáculos diferentes. No Brasil, uma dificuldade comum é a falta de acesso às tecnologias digitais por parte de muitos estudantes economicamente desfavorecidos. Mesmo assim, o ensino à distância/remoto tem acontecido. Em se tratando da Educação Física, matéria voltada para o ensino da cultura corporal de movimento, as aulas requerem espaços amplos para sua efetivação e os conteúdos costumam ser desenvolvidos de forma procedimental, conforme classificação de Zabala (1998), embora também ocorram momentos voltados ao desenvolvimento de suas perspectivas conceitual e atitudinal.

Diante desta realidade, muitas questões requerem atenção dos pesquisadores e pesquisadoras e uma delas diz respeito às relações estabelecidas entre Educação Física e mídia. Considerando a literatura, Santos et al. (2014) apresentam um panorama acerca da produção científica envolvendo a temática em periódicos nacionais, no período compreendido entre os anos de 2006 e 2012. O estudo mostra que até aquele momento existia grande interesse pela análise de produtos midiáticos, o que entre os anos de 1990 e 2005 era majoritariamente ligado à temática esportiva e depois foi se ampliando para outros enfoques como a divulgação de modelos corporais supostamente ideais. O mesmo estudo ainda compreende abordagens voltadas à inserção das ferramentas midiáticas no processo ensino e aprendizagem, o que aparece em segundo lugar considerando o percentual geral.

Apesar disso, ao analisar algumas experiências com a mídia-educação no contexto de um curso de graduação em Educação Física no Brasil, Bianchi e Pires (2015) constatam que existem poucas propostas educativas voltadas à exploração de possibilidades atreladas às tecnologias de informação e comunicação. Dada a escassez, os autores sugerem dificuldades a serem enfrentadas pelos profissionais para promoverem intervenções pedagógicas a partir de diferentes perspectivas da mídia-educação, tais como: técnico-instrumental; objeto de estudo ou crítica; produtivo-expressiva.

Assim, levando em conta a necessidade de desenvolver novos estudos para compreender a atualidade, objetivamos mapear as produções acadêmicas que envolvem o contexto "Educação Física e Mídia" na base Web of Science, considerando o período entre 1945 a 2019 e identificar como a mídia é tangenciada pela Educação Física nesses estudos, refletindo sobre os achados. Isto é feito a partir de um exame bibliométrico, acompanhado de uma Análise de Conteúdo. A opção pela Bibliometria se dá com base em Job (2018), que ilumina sua utilização no campo da Educação Física e afirma se tratar de uma estratégia útil para analisar determinada área ou recorte do conhecimento, o que permite, dentre outros aspectos, a identificação de lacunas. $\mathrm{Na}$ concepção da autora isto pode ser mais bem explorado ao incluirmos análises 
qualitativas, o que neste estudo permitirá melhor visualização acerca da essência das publicações resgatadas, além do espaço ocupado por cada uma delas na literatura.

\section{PROCEDIMENTOS METODOLÓGICOS}

Iniciamos pela descrição dos procedimentos ligados ao exame bibliométrico. Segundo Moreno-Ceja (2010), o método é útil para expor a atividade científica e tecnológica de um campo do conhecimento, o que pode ser feito de maneira ampla, considerando toda a atividade, ou de forma particular, selecionando apenas determinados recortes da área pesquisada. Assim, por meio da Figura 1 detalhamos a trajetória percorrida para sua efetivação:

Figura 1 - Etapas da pesquisa bibliométrica.

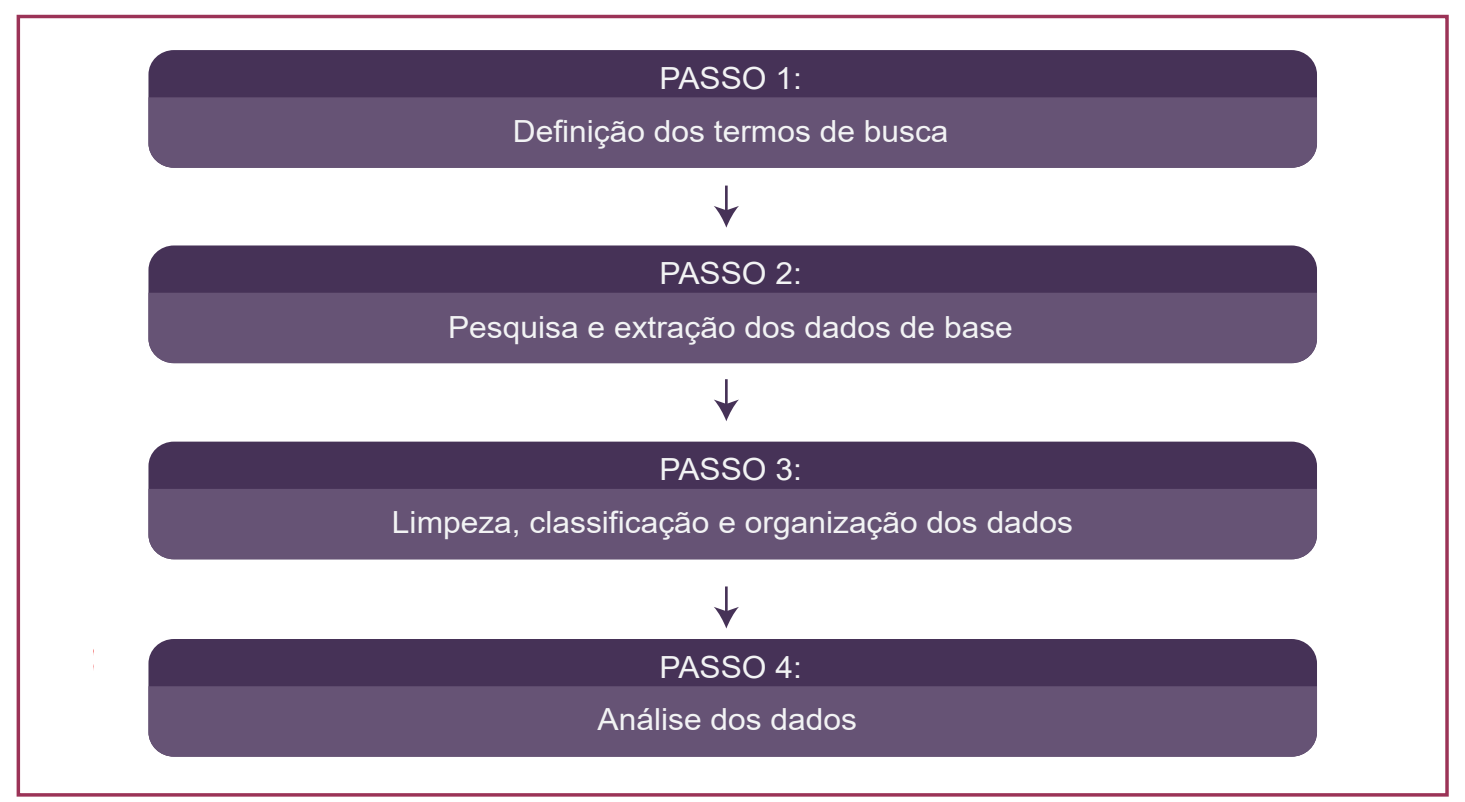

Fonte: Adaptado de Guimarães, Ribeiro e Azevedo-Ferreira (2018).

A definição dos termos de busca mencionada no passo 01 foi norteada por uma pesquisa bibliográfica direcionada à identificação de estudos que continham a relação "Educação Física e Mídia". No processo de busca combinamos os termos "physical education" com "media" ou "social media" ou "mobile app" ou "social network". As expressões foram colocadas entre aspas duplas para que a procura retornasse somente o conjunto envolvendo as palavras juntas. Esclarecemos que testamos outros termos, como "TV", "newspaper", mas não houve diferença no quantitativo obtido. Isto ocorreu porque nessas ocasiões a palavra "mídia" também estava presente, diferentemente do que aconteceu em alguns casos, quando acrescentamos os termos mencionados anteriormente. Evidenciamos que o sentido da palavra "mídia" adotado aqui é o mesmo utilizado por Betti e Pires (2005), ou seja, diz respeito aos meios de comunicação. Nesta perspectiva, a mídia também é indústria, ao passo que produz e veicula símbolos e significados atrelados à cultura.

Ressaltamos que todos os documentos recuperados da base de dados contêm o termo "physical education", associado ao menos a um dos outros termos, como evidente na Figura 2, que representa graficamente a estratégia: 
Figura 2 - Estratégia de busca

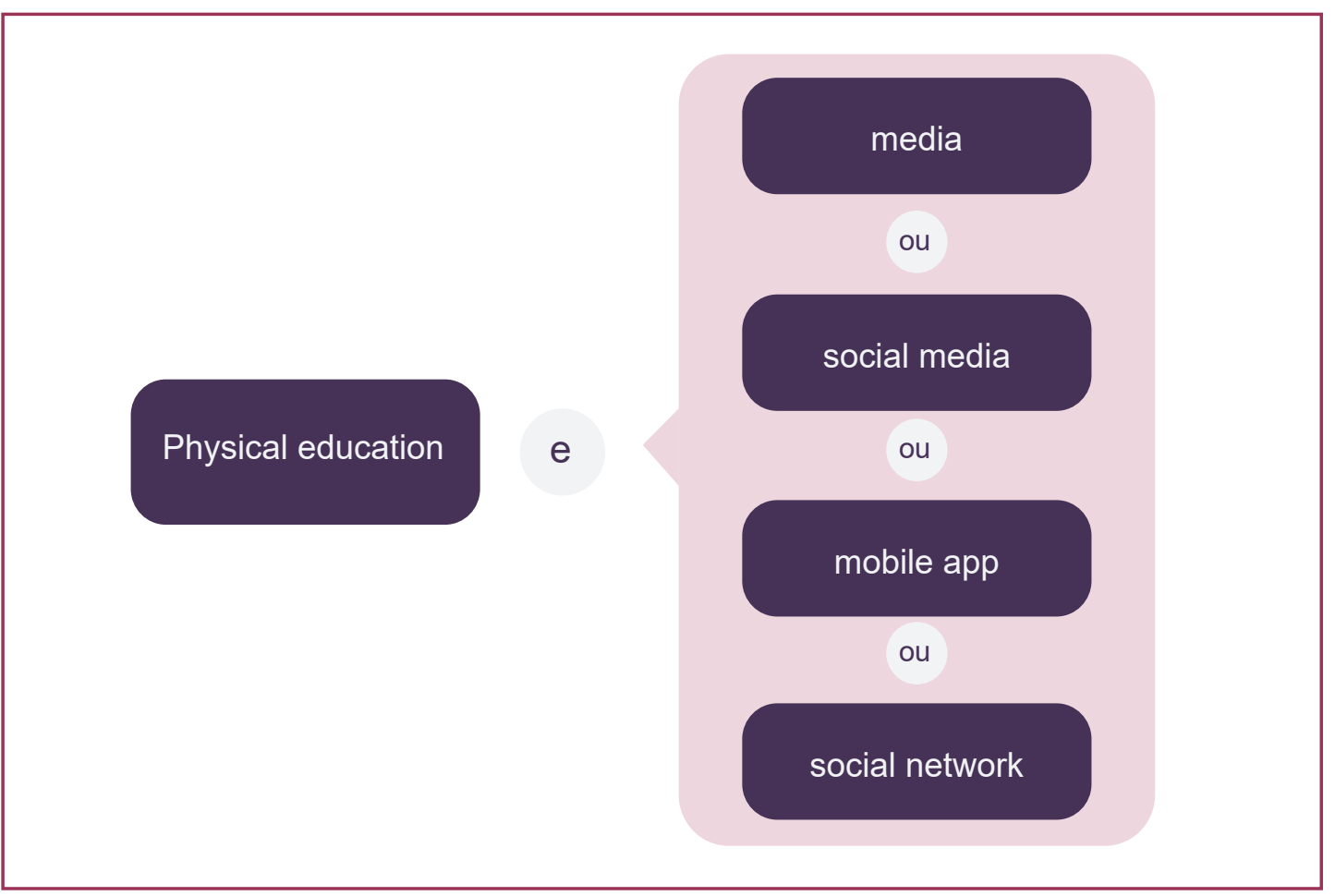

Fonte: Elaborado pelos autores.

A busca foi realizada por Tópicos, isto quer dizer que, para o retorno dos resultados, vasculhamos o título dos documentos, o resumo e as palavras-chave.

No passo 02, optamos pela utilização da base de dados presente na coleção principal da Web of Science (WoS). Para Chen (2010) e Moreno-Ceja (2010) a mesma possui escopo abrangente, o que é bastante adequado à preparação de estudos bibliométricos.

Quanto ao período, a coleta de dados foi realizada no dia 20 de janeiro de 2020, compreendendo o período de 1945 até 2019. Esclarecemos que o ano de 1945 é o primeiro limite disponibilizado pela WoS e o ano de 2020 foi desconsiderado, uma vez que ainda estava em curso no momento da coleta. A inclusão de praticamente todo o período disponível até o momento de extração dos dados da base se justifica pela inexistência de qualquer estudo bibliométrico sobre o tema em foco, o que justificaria dispensar determinado período.

Foram resgatados documentos dos seguintes tipos: Article, Proceedings Paper, Review, Meeting Abstract, Book Review e Editorial.

No passo 03 utilizamos o VantegePonit V.12, um software para mineração de dados. Através dele foi possível excluir documentos que não faziam parte do escopo da pesquisa. Para isto foi necessário ler todos os títulos e resumos dos documentos. A exclusão era efetivada sempre que os termos não apresentavam relação de sentido. Também foram realizadas padronizações nos campos autores, países e instituições, pois como a base de dados reúne documentos de diversas fontes, é possível encontrar diferentes denominações fazendo referência ao mesmo item, como por exemplo, o nome por extenso de uma instituição de ensino e sua sigla. 
Ainda utilizando o software, construímos as listas, matrizes e redes de colaboração que apresentaremos adiante.

Para a análise de dados, utilizamos a estatística descritiva, análise de redes e os seguintes indicadores bibliométricos: produção, colaboração e temática de produção. Os detalhes de cada indicador bibliométrico estão presentes no Quadro 1.

Quadro 1 - Indicadores bibliométricos utilizados na pesquisa.

\begin{tabular}{|c|c|}
\hline Indicadores bibliométricos & Definição \\
\hline Indicadores de Produção (SANCHO, 1990) & $\begin{array}{c}\text { São contagens de documentos, fornecem informações } \\
\text { sobre ascensão ou declínio de uma disciplina do } \\
\text { conhecimento científico e grupos de pesquisas. }\end{array}$ \\
\hline $\begin{array}{c}\text { Colaboração } \\
\text { (CASADO e MORENO, 1997; SÁNCHEZ, }\end{array}$ & $\begin{array}{c}\text { Permite identificar países, instituições e autores } \\
\text { que assinam o documento em colaboração. Quanto } \\
\text { maior o grau de colaboração, maior será o grau } \\
\text { de profissionalização da pesquisa, uma vez que } \\
\text { as instituições se organizam em torno e equipes } \\
\text { especializadas. }\end{array}$ \\
\hline $\begin{array}{c}\text { Temáticas da Produção } \\
\text { (MORENO-CEJA, 2010) }\end{array}$ & $\begin{array}{c}\text { São agrupamentos da produção científica. Permite } \\
\text { conhecer as temáticas dos campos científicos e sua } \\
\text { frequência de publicação. }\end{array}$ \\
\hline
\end{tabular}

Fonte: Adaptado de Azevedo-Ferreira, Santos-Souza e Alves (2018).

Por último, desenvolvemos a Análise de Conteúdo na perspectiva de Bardin (2011). Através dela, detectamos como a mídia foi tangenciada pela Educação Física em todos os estudos extraídos da WoS. Isto ocorreu a partir da leitura de todos os Tópicos, ou seja, título do documento, resumo e palavras-chaves. Uma planilha do Excel favoreceu a organização desta ação, que resultou na elaboração de categorias. A mesma foi construída, distribuindo em colunas os títulos, resumos, palavras-chave e por último as categorias, que serão apresentadas junto aos resultados, onde evidenciamos a essência de cada constituição. Esclarecemos que em alguns casos não foi possível formular as categorias apenas com a análise dos Tópicos, então recorreremos ao texto em sua integralidade para compreender o contexto envolvendo Educação Física e mídia.

Nesta etapa, o VantegePonit V.12 foi útil para demonstrar a ligação entre categorias, bem como seus pontos de intercessão. Isto porque uma publicação pode resultar em diferentes classificações, já que a mídia pode ser tangenciada de diferentes maneiras no mesmo texto, o que também ficará explícito na apresentação das análises.

\section{RESULTADOS}

Foram recuperados o total de 232 registros da Base de dados da Web of Science (WoS). Os mesmos estão distribuídos ao longo dos anos, conforme a Figura 3. Podemos notar que o primeiro registo aparece no ano de 1992, o segundo em 1999 e somente a partir do ano de 2002 passou a existir registros anuais. O destaque é para o ano de 2017, quando ocorreram 32 publicações. 
Figura 3 - Indicadores de produção.

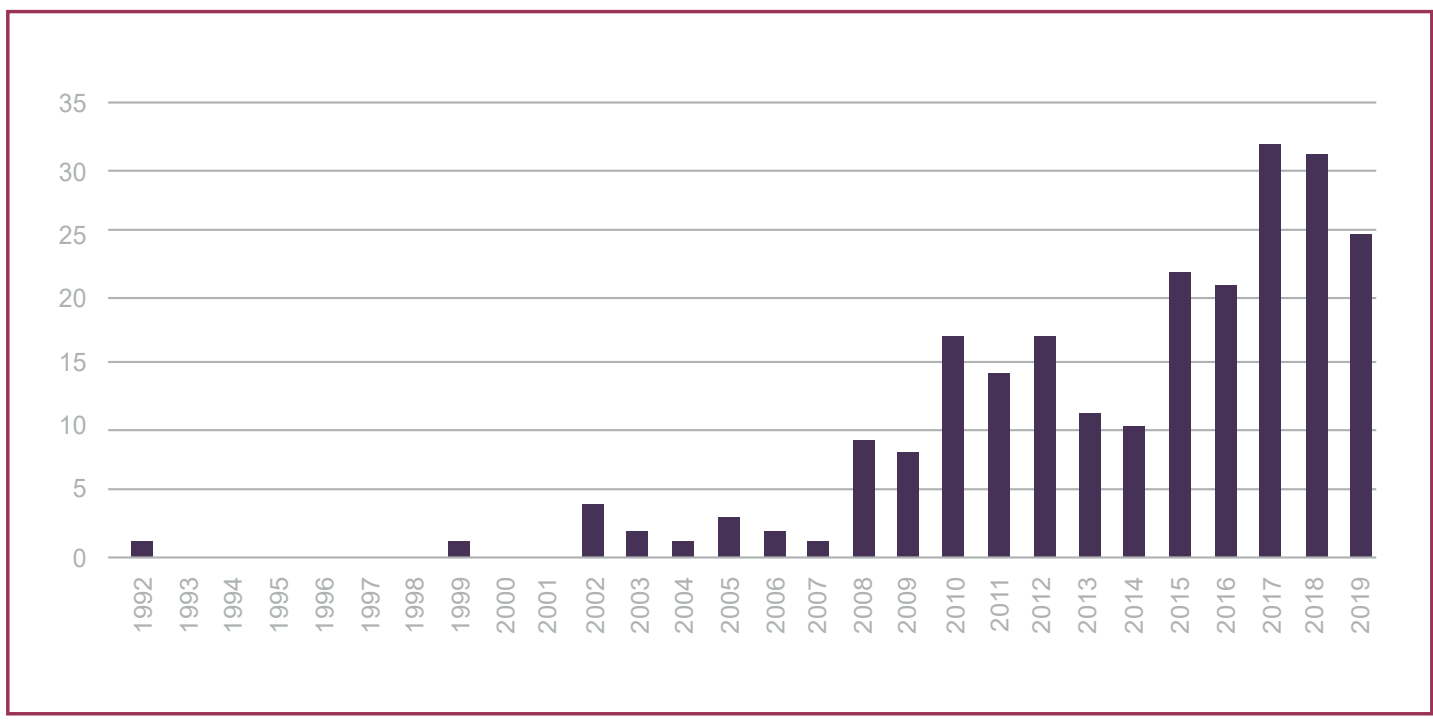

Fonte: Elaborado pelos autores com base nos dados da pesquisa.

Dentre os países que mais publicaram sobre o tema estão: Estados Unidos, China, Brasil e Reino Unido. A soma de todas as publicações destes quatro países sobre o tema equivale a $51,6 \%$ do total. A Figura 4 mostra a distribuição de cada um deles.

Figura 4 - Principais países que publicaram sobre o tema.

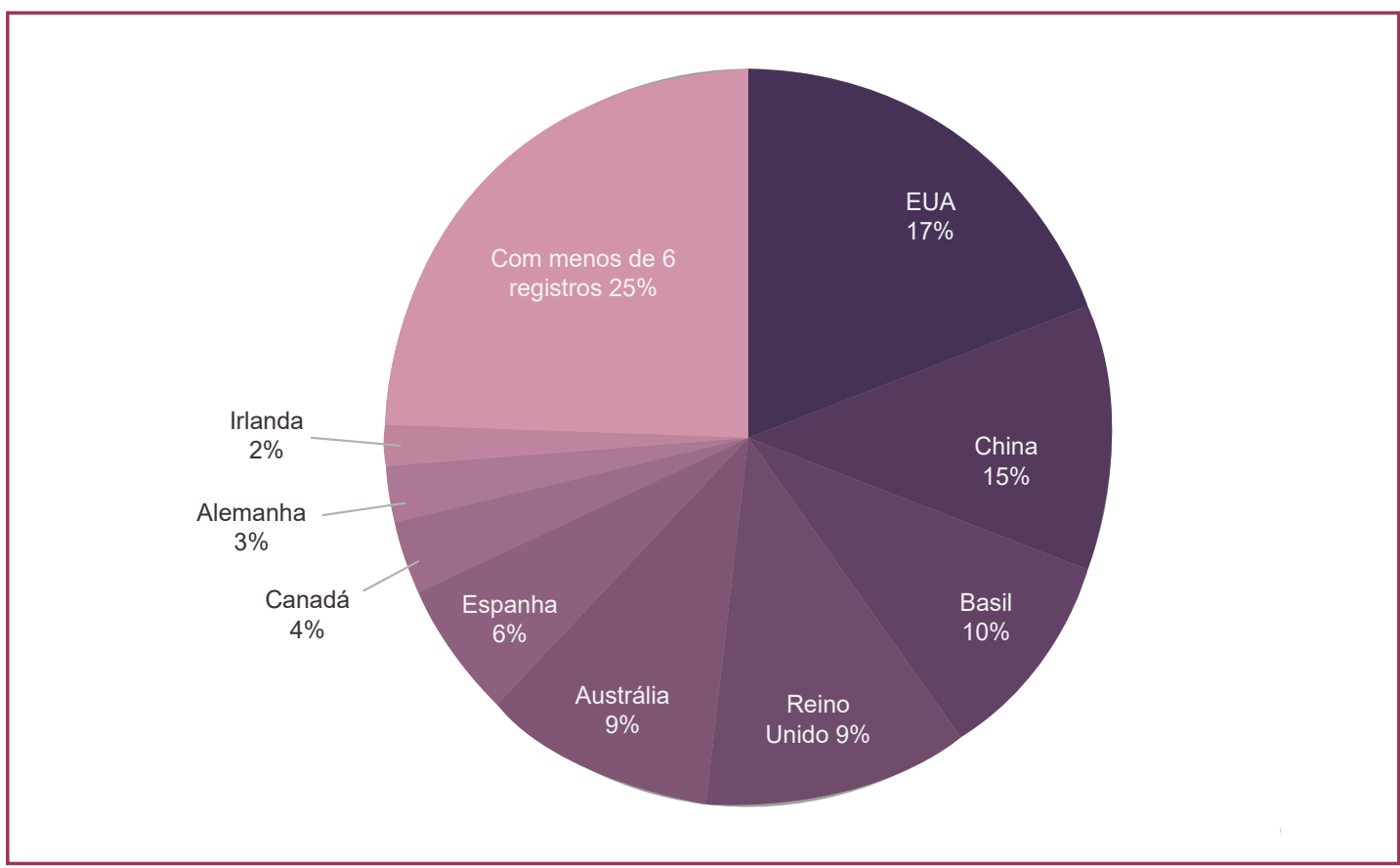

Fonte: Elaborado pelos autores com base nos dados da pesquisa.

Cabe destacar que um país pode publicar em parceria com outros, sendo este registro contabilizado para ambos. A Figura 5 mostra a rede de colaboração entre os países. 
Figura 5 - Rede de colaboração entre países que publicaram sobre o tema.

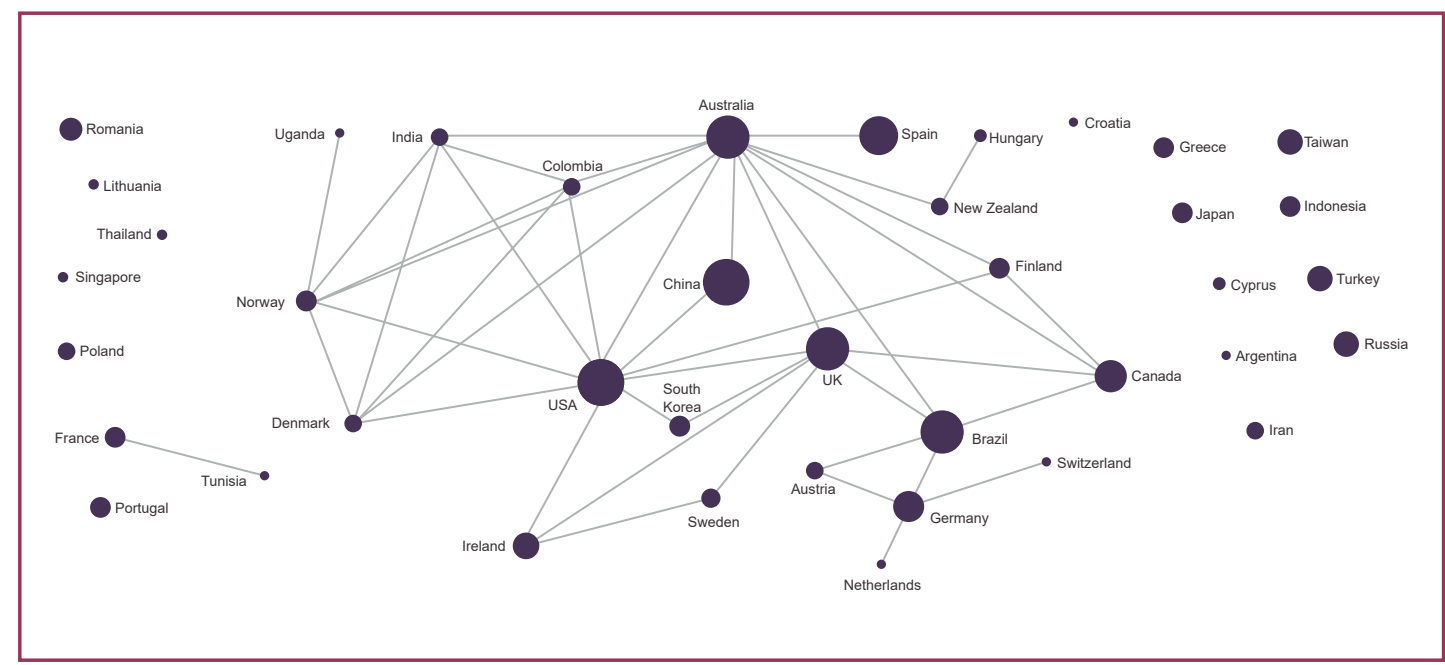

Fonte: Elaborado pelos autores com base nos dados da pesquisa.

A rede de coautoria entre os países (Figura 5) demonstra que Estados Unidos, China, Brasil e Reino Unido se conectam com diversos outros países, entretanto muitos ainda publicam sem parceria internacional.

Através da Figura 6 constatamos que muitos países (coloridos de cinza) ainda não publicam sobre o tema, com destaque para países da África e da América Latina.

Figura 6 - Países que publicaram sobre o tema.

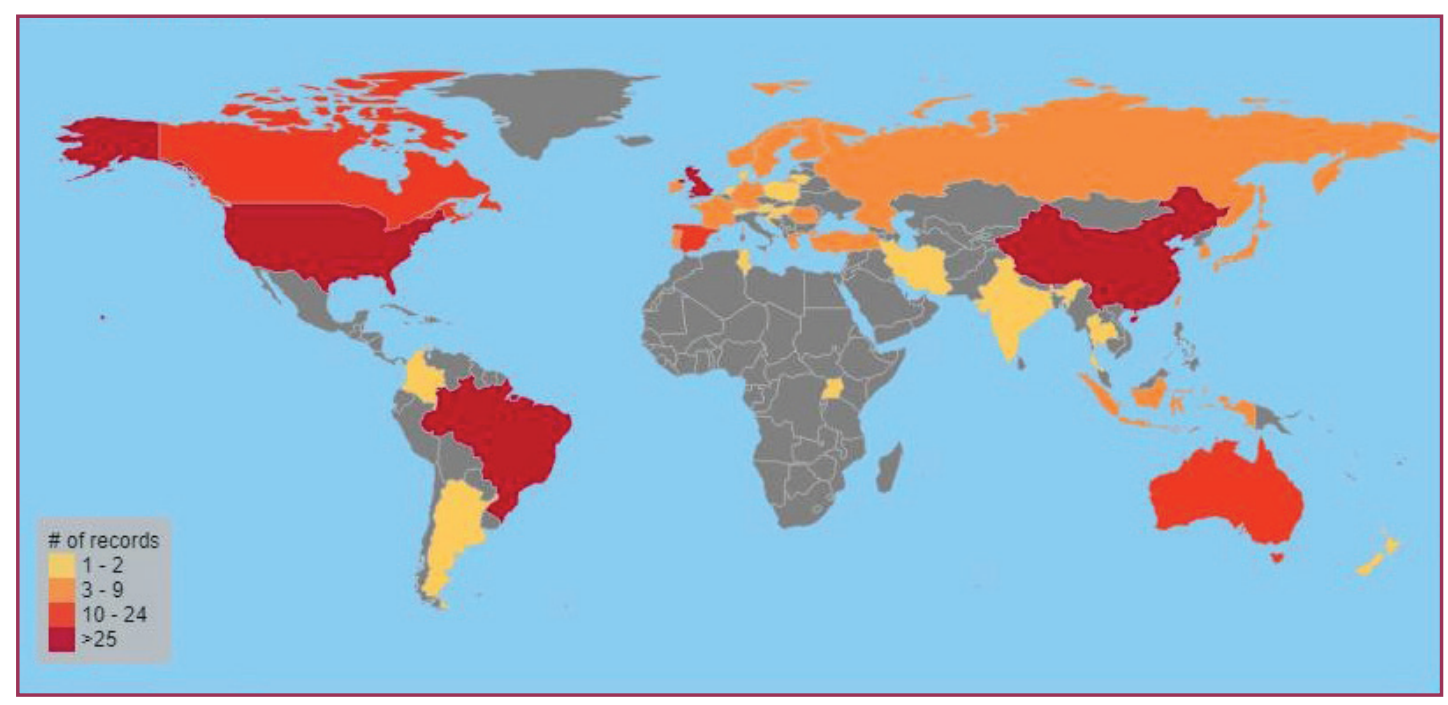

Fonte: Elaborado pelos autores com base nos dados da pesquisa.

Quanto às instituições, encontramos 305 registros na base de dados da WoS. As organizações que mais publicaram estão apresentadas na Tabela 1. Totalizaram maior número de publicações a University Loughborough com nove documentos, ocupando o primeiro lugar e em segundo estão a University of Birmingham e a Universidade Federal de Santa Catarina (UFSC) com seis publicações cada uma. 
Tabela 1 - Instituições que mais publicaram sobre o tema.

\begin{tabular}{cc}
\hline Registros & Instituições \\
\hline 9 & University Loughborough \\
6 & University of Birmingham \\
6 & Universidade Federal de Santa Catarina \\
5 & Columbia University \\
5 & University of Bedfordshire \\
5 & University of Limerick \\
5 & University of Queensland \\
4 & Griffith University \\
4 & Kent State University \\
4 & University of Alabama \\
4 & University of British Columbia \\
4 & University Granada \\
4 & Universidade Estadual de Campinas \\
4 & Universidade Estadual Paulista \\
\hline
\end{tabular}

Fonte: Elaborado pelos autores com base nos dados da pesquisa.

A Figura 7 apresenta a rede de colaboração entre as instituições que publicaram sobre o tema. Para esta representação, consideramos apenas as organizações que divulgaram pelo menos dois documentos.

Figura 7 - Rede de colaboração entre organizações.

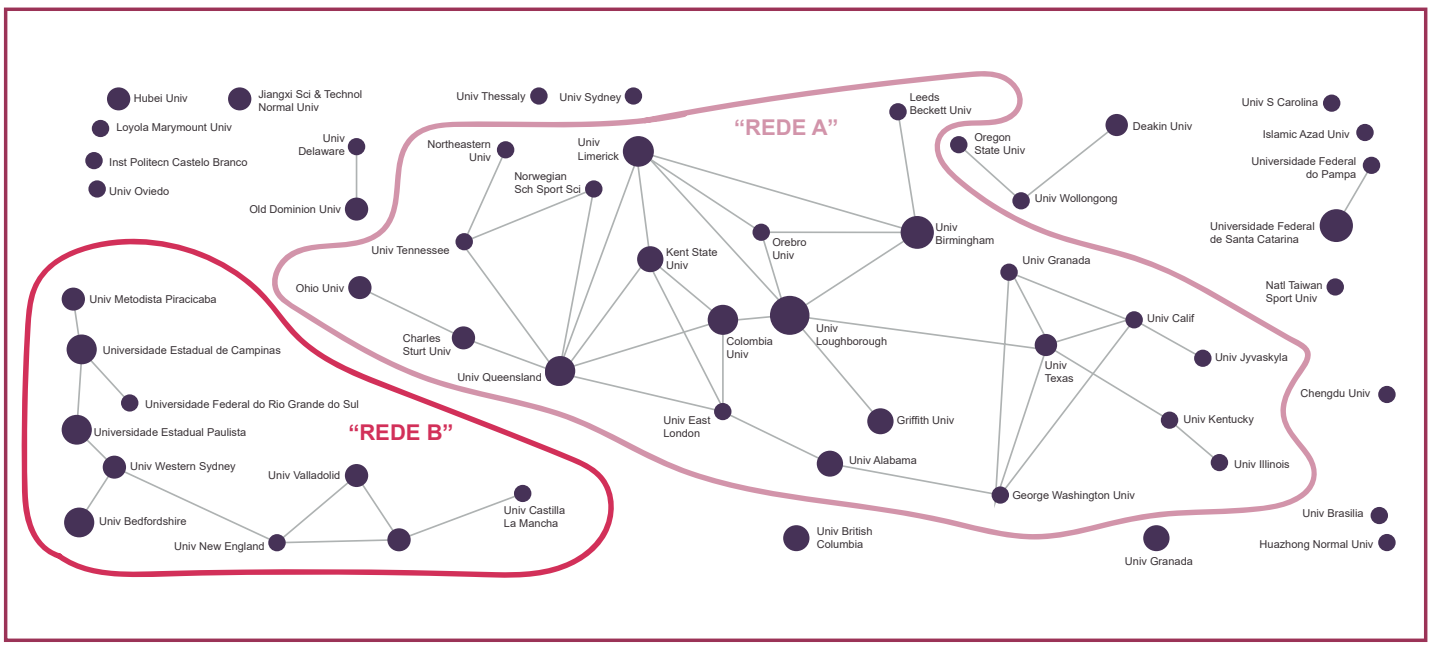

Fonte: Elaborado pelos autores com base nos dados da pesquisa.

Podemos notar, a partir da Figura 7, que há duas redes bem definidas, ou seja, a "Rede A", composta pelo maior número de universidades, mas sem a presença de universidades brasileiras; e a "Rede B", em que verificamos cinco universidades brasileiras publicando em conjunto. Também é possível que observar que ela compreende cooperação internacional. Evidenciamos que a UFSC não está presente nessas duas redes, ligando-se apenas à Universidade Federal do Pampa, por meio de duas publicações.

$\mathrm{Na}$ Tabela 2 apresentamos as instituições brasileiras que publicaram sobre o tema. Salientamos que $77,27 \%$ das produções são provenientes de organizações 
públicas, especificamente Universidades e Institutos Federais. Somente 22,73\% de toda a publicação nacional pertencem a organizações privadas.

Tabela 2 - Organizações brasileiras que publicaram sobre o tema.

\begin{tabular}{|c|c|c|}
\hline Ranking & Organizações & Publicações \\
\hline 1 & Universidade Federal de Santa Catarina & 6 \\
\hline \multirow{2}{*}{2} & Universidade Estadual de Campinas & 4 \\
\hline & Universidade Estadual Paulista & 4 \\
\hline 3 & Universidade Metodista de Piracicaba & 3 \\
\hline \multirow{4}{*}{4} & Universidade Federal do Pampa & 2 \\
\hline & Universidade de Brasília & 2 \\
\hline & Universidade Federal do Rio Grande do Sul & 2 \\
\hline & Instituto Federal de Goiás & 2 \\
\hline \multirow{19}{*}{5} & Instituto Federal do Amapá & 1 \\
\hline & Instituto Federal Sudeste MG, Campus Juiz de Fora & 1 \\
\hline & Faculdade Terra Nordeste & 1 \\
\hline & Centro de Ensino Superior do Amapá & 1 \\
\hline & Universidade Federal de Juiz de Fora & 1 \\
\hline & Universidade Salgado de Oliveira & 1 \\
\hline & Centro de Estudos Avançados Pós-Graduação e Pesquisa & 1 \\
\hline & Instituto Federal do Amazonas & 1 \\
\hline & Universidade de Ribeirão Preto & 1 \\
\hline & Universidade Federal do Amapá & 1 \\
\hline & Universidade Federal do Ceará & 1 \\
\hline & Universidade Federal do Espírito Santo & 1 \\
\hline & Universidade Federal do Paraná & 1 \\
\hline & Universidade Presbiteriana Mackenzie & 1 \\
\hline & Universidade Santa Cecília & 1 \\
\hline & Universidade Estadual de Londrina & 1 \\
\hline & Universidade Federal de Sergipe & 1 \\
\hline & Universidade Federal do Rio de Janeiro & 1 \\
\hline & Universidade Gama Filho & 1 \\
\hline
\end{tabular}

Fonte: Elaborado pelos autores com base nos dados da pesquisa.

Considerando a área de conhecimento, as publicações se concentram principalmente nos campos das Ciências Humanas, Ciências da Saúde e Ciências Sociais Aplicadas, somando aproximadamente $87 \%$ de todas as publicações da área. A Figura 8 demonstra a porcentagem de publicações por cada grande área. 
Figura 8 - Grandes áreas de pesquisa.

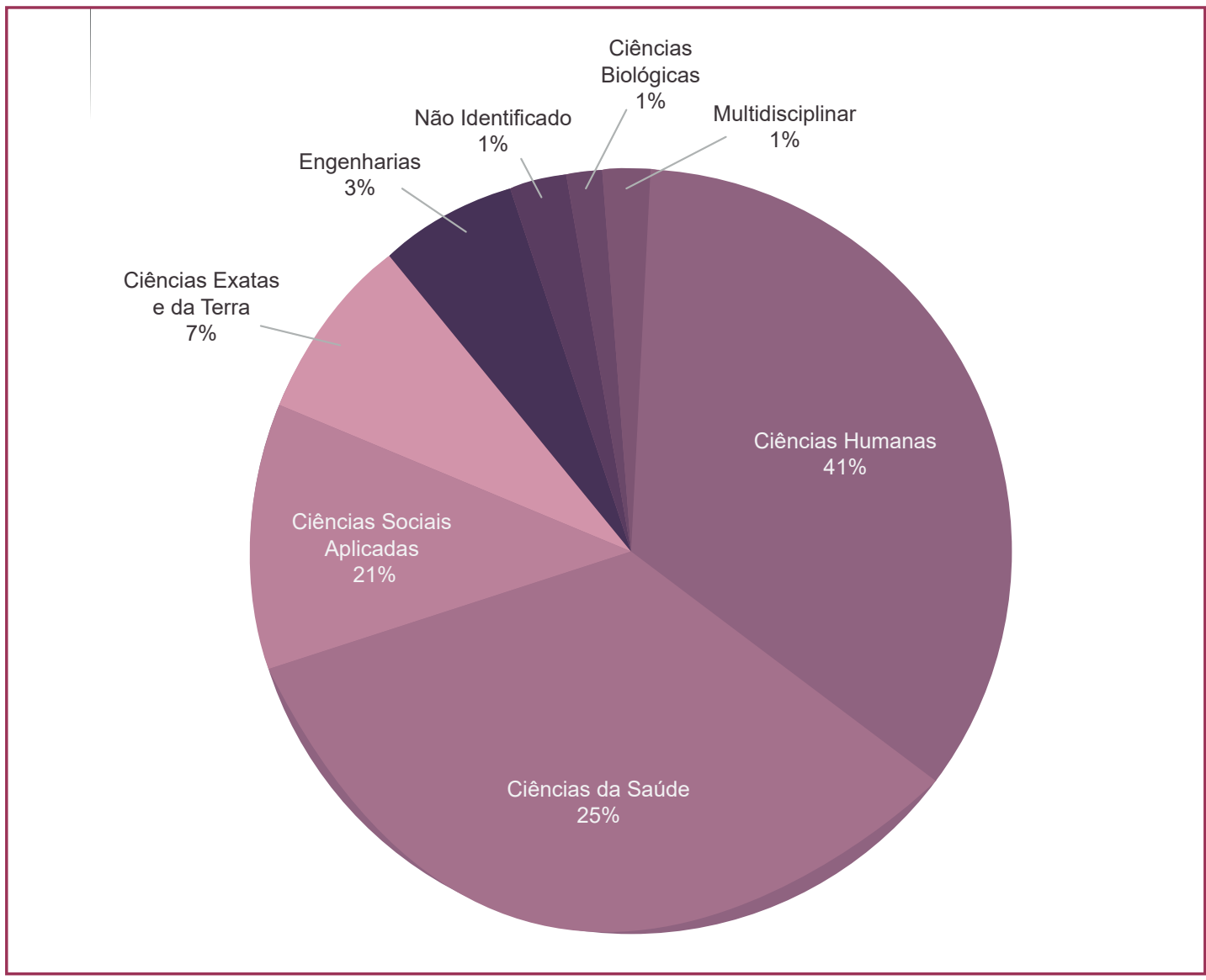

Fonte: Elaborado pelos autores com base nos dados da pesquisa.

Destacamos ainda que a mesma publicação pode se enquadrar em mais de uma grande área de pesquisa, como evidente na Figura 9.

Figura 9 - Redes de colaboração entre grandes áreas de pesquisa.

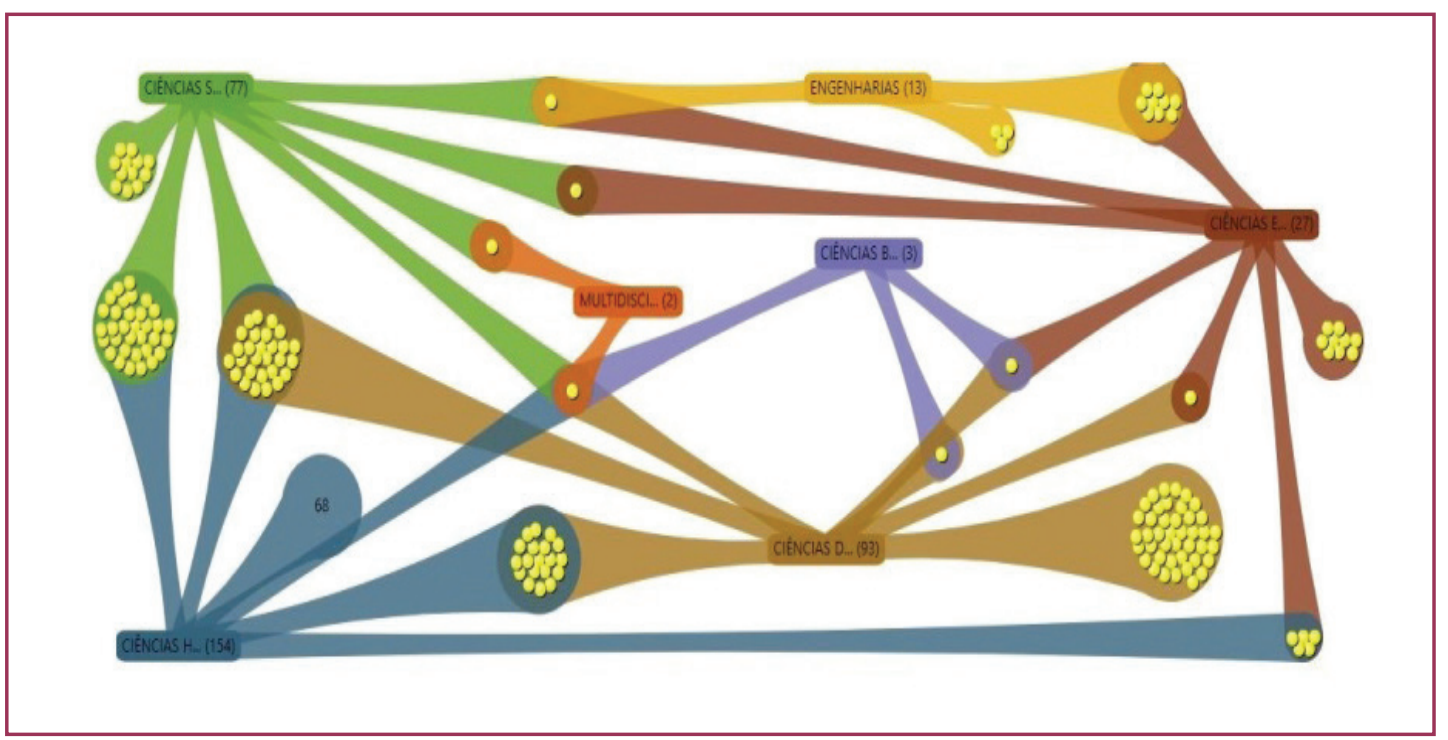

Fonte: Elaborado pelos autores com base nos dados da pesquisa.

A Tabela 3 resultou da Análise de Conteúdo. Ela apresenta as categorias que concentram a essência de todas as abordagens, ou seja, expressam como que a mídia foi tangenciada em cada estudo que fez parte da Bibliometria. 
Tabela 3 - Como a mídia é tangenciada nos estudos

\begin{tabular}{lcc}
\hline \multicolumn{1}{c}{ Categorias } & Registros & $\%$ \\
\hline Agente influenciador da formação de subjetividades & 103 & $44,40 \%$ \\
Recurso didático & 66 & $28,45 \%$ \\
Objeto de análise & 51 & $21,98 \%$ \\
Meio para coleta de dados & 23 & $9,91 \%$ \\
Fator que impacta no nível de atividade física & 19 & $8,19 \%$ \\
Recurso utilizado para desenvolvimento profissional & 13 & $5,60 \%$ \\
Educação midiática & 10 & $4,31 \%$ \\
Fonte de informação & 7 & $3,02 \%$ \\
Meio de divulgação esportiva & 4 & $1,72 \%$ \\
Meio para promover a educação à distância & 4 & $1,72 \%$ \\
Recurso utilizado para avaliar & 3 & $1,29 \%$ \\
Fator a ser considerado na elaboração do currículo & 2 & $0,86 \%$ \\
Fator que impacta na gestão esportiva & 1 & $0,43 \%$ \\
Fator que impacta no desempenho escolar & 1 & $0,43 \%$ \\
Fator que impacta no desempenho motor & 1 & $0,43 \%$ \\
Recurso para evolver pais no processo ensino-aprendizagem de alunos & 1 & $0,43 \%$ \\
Recurso utilizado para gestão do ensino & 1 & $0,43 \%$ \\
\hline \multicolumn{2}{c}{ * } & 7 Fara o cálculo das porcentagens, foi considerado o total dos registros resgatados na \\
\hline
\end{tabular}

Podemos observar que a categoria "Agente influenciador da formação de subjetividades" está presente em $44,4 \%$ dos documentos resgatados. "Recurso Didático" figura em segundo com 28,45\%, e "Objeto de Análise", em terceiro, sendo tangenciada em 21,98 \% dos estudos. Cabe lembrar que uma publicação pode tangenciar a mídia de diferentes maneiras, por isso o somatório dos registros é superior à quantidade de documentos encontrados na busca. Por exemplo, ao mesmo tempo em que a mídia é mencionada como agente influenciador de opinião, ela pode ser requisitada para coletar dados e ainda ser foco de análise.

Abaixo evidenciamos a essência que resultou na constituição de cada uma das categorias:

a) Agente influenciador da formação de subjetividades: diz respeito às menções que admitem a influência da mídia sobre a formação de opinião do público, considerando variados aspectos como: representações sobre a Educação Física; imagem e padrão corporal; estímulo à adesão de hábitos considerados saudáveis; questões de gênero; representação esportiva; fatores de risco para a saúde; representação de brincadeiras lúdico-agressivas; diversidade étnica; consumo; nacionalismo a partir do esporte; representação social de alunos deficientes nas aulas de Educação Física; desenvolvimento moral, entre outros;

b) Recurso didático: refere-se ao uso instrumental da mídia como estratégia metodológica para ensino de conteúdos nos diferentes segmentos educacionais, contemplando ensino de valores, ensino de movimentos técnicos, desenvolvimento do raciocínio lógico, ensino do vocabulário esportivo em língua inglesa, abordagem 
crítica sobre imagem e padrão corporal, bem como sobre adesão de hábitos considerados saudáveis, entre outros;

c) Objeto de análise: diz respeito às ocasiões em que um veículo ou produção midiática é o foco do processo analítico tratado cientificamente. Essas apreciações contemplaram, por exemplo, representação esportiva, uso de tecnologias para ensino-aprendizagem de movimentos técnicos, questões de gênero, diversidade étnica, estímulo à adesão de hábitos considerados saudáveis, entre outras;

d) Meio para coleta de dados: abrange situações em que a mídia é utilizada como uma via para coletar dados com fins científicos, o que inclui a extração de recortes provenientes de seus veículos ou como uma estratégia para aplicação de instrumentos previamente elaborados;

e) Fator que impacta o nível de atividade física: constitui-se a partir de contextualizações em que o uso da mídia é apontado como variável que interfere no volume de atividade física praticado por um indivíduo;

f) Recurso utilizado para desenvolvimento profissional: refere-se ao uso da mídia para fins de aprimoramento profissional por parte dos professores de Educação Física;

g) Educação midiática: trata-se das abordagens em que a mídia ou suas produções são discutidas a partir de uma perspectiva pedagógica voltada para o desenvolvimento da criticidade dos alunos. A categoria compreende o trato de temas ligados ao estímulo à adesão de hábitos considerados saudáveis, questões de gênero, diversidade étnica, imagem e padrão corporal, consumo e temas ligados ao esporte.

h) Fonte de informação: envolve situações em que a mídia é mencionada como um recurso para obter informações sobre variados assuntos, como doping, abuso sexual infantil no meio esportivo, ensino-aprendizagem de movimentos, transtornos de imagem corporal, entre outros.

i) Meio de divulgação esportiva: abrange a divulgação de modalidades como basquete, parkour, futebol e também esporte olímpico e paralímpico.

j) Meio para promover educação à distância: recurso para efetivar ensino na modalidade à distância;

k) Recurso utilizado para avaliar: relativo ao uso da mídia como recurso para avaliar a aprendizagem de determinado conteúdo;

I) Fator a ser considerado na elaboração do currículo: constituído por menções que reconhecem a necessidade de atentar para diferentes perspectivas ligadas à mídia e considerá-las durante o processo de formação.

m) Fator que impacta na gestão esportiva: pensada a partir de menções que consideram a mídia como um fator que impacta na gestão de determinado esporte.

n) Fator que impacta o desempenho escolar: relaciona-se a contextualizações em que o uso da mídia é apontado como variável que intervém no desempenho do aluno;

o) Fator que impacta no desempenho motor: inclui contextualizações em que o uso da mídia é apontado como variável que interfere no desenvolvimento de habilidades motoras;

p) Recurso para envolver pais no processo ensino-aprendizagem de alunos: categoria 
constituída em função de abordagem específica, que denota exclusivamente o enfoque presente em seu enunciado;

q) Recurso utilizado para gestão do ensino: compreende situações em que os recursos tecnológicos, tais como plataformas digitais foram requisitadas para administrar os registros relativos ao processo educativo.

Na Figura 10 podemos observar como se dá a relação entre as diversas formas com que a mídia foi abordada nos estudos. Os nós representam o modo como ela foi tangenciada e os laços os pontos de intercessão. Ressaltamos que a ausência de laços significa que determinados documentos se referiram à mídia apenas de uma forma.

Figura 10 - Rede de relacionamento sobre as formas com que a mídia é tangenciada nos estudos.

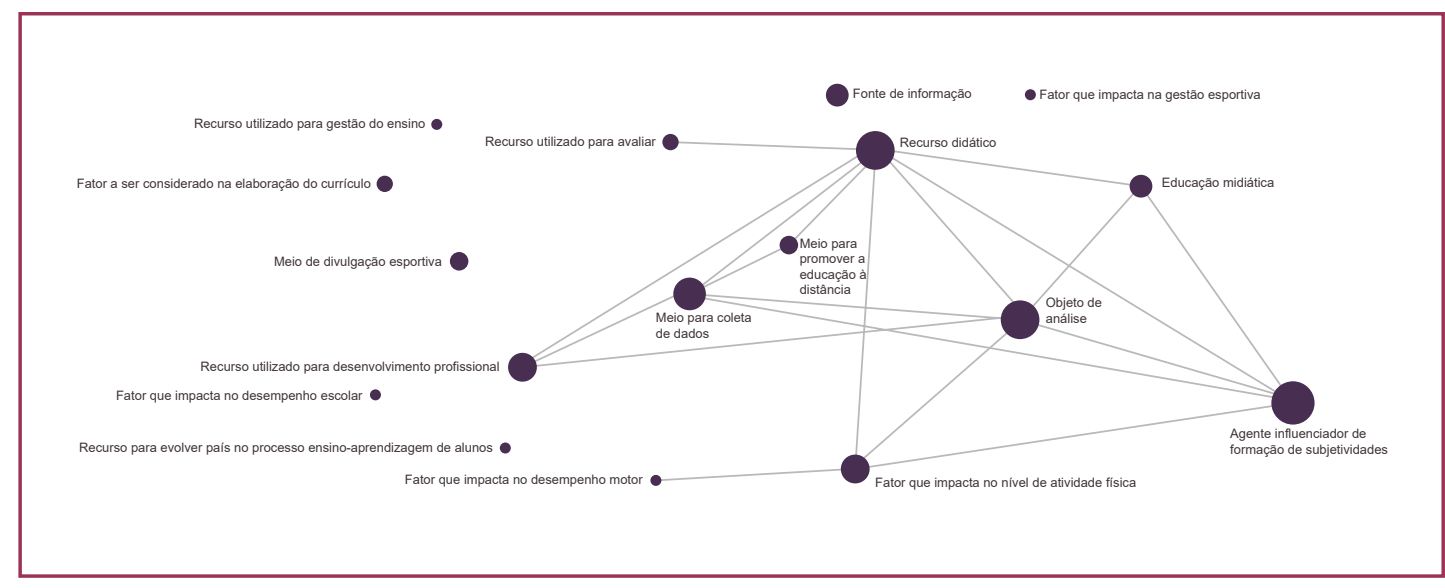

Fonte: Elaborado pelos autores com base nos dados da pesquisa.

\section{DISCUSSÃO}

Partindo da ordem de apresentação dos resultados e considerando os aspectos gerais do mapeamento, iniciamos pelo volume de publicações. Como a mídia está entranhada no cotidiano, julgamos baixo o quantitativo de 232 registros na WoS, uma base internacional. Isto demonstra que estamos diante de um tema emergente. Também é instigante pensar que só a partir do ano 2002 as produções foram alavancadas, conforme exposto na linha histórica exibida na Figura 3. Fica evidente que ocorreu uma mudança de cenário, pois até então a escassez era ainda maior. Mesmo considerando o período remoto, desde 1945, observamos que somente a partir de 1992 é possível encontrar publicações envolvendo a temática "Educação Física e mídia" na WoS. Em se tratando da realidade brasileira, é importante atentar para um fator apontado por Lins (2013), que certamente impactou na forma de divulgar as produções, ou seja, a implantação da internet no Brasil com a finalidade de comunicar produções acadêmicas ocorreu somente em 1989. Olhando para o cenário atual, os dados presentes no mapeamento possibilitam aos pesquisadores uma reflexão sobre a projeção de seus estudos, sobre a necessidade ou não de divulgá-los em revistas indexadas na WoS.

As Figuras 4, 5 e 6 mostram que o tema não é de interesse global. Além disso, a Figura 5 retrata a baixa ou inexistente colaboração internacional entre 
alguns países, a exemplo, Portugal, Grécia e Rússia. A Figura 7 apresenta a rede de colaboração entre as instituições, sendo um reflexo da ligação entre os países (Figura 5). Observando o contexto internacional, constatamos que a dificuldade de interação não é uma questão particular de poucas instituições.

No que se refere à Tabela 1 , que expõe sobre o volume de produções de acordo com a instituição, constatamos a representatividade do Brasil, que aparece três vezes, sendo uma delas em segundo lugar. Também chama atenção que a maioria das produções é realizada pela iniciativa pública em Universidades Federais, Estaduais e Institutos Federais (Tabela 2), com destaque para aquelas localizadas na Região Sul do país, principalmente a UFSC. O Brasil ainda se destaca em relação à colaboração internacional (Figura 5), mas, apesar do cenário positivo no contexto mundial, é importante frisar que a totalidade é formada por um quantitativo baixo, assim não há muito o que comemorar.

Por outro lado, considerando a representatividade das publicações brasileiras no contexto geral, apresentamos algumas particularidades que favorecem a compreensão de determinados pontos, como, por exemplo, em relação ao quantitativo, que pode ser atribuído à ampliação e ao amadurecimento das subáreas sociocultural e pedagógica da Educação Física. Lüdorf e Castro (2017) afirmam que na década de 1990 houve avanços significativos rumo à consolidação dos cursos de pós-graduação em Educação Física no Brasil, principalmente destas subáreas, que acrescentaram novos olhares à profissão. E no que se referem à internacionalização dos estudos, os autores apontam uma mudança no modo de divulgar o conhecimento, já que no primeiro momento isto era feito por meio de livros, sendo a submissão em periódicos um fenômeno bastante recente. Vale retomar que somente em 1989 a internet passa a ser utilizada para fins de divulgação acadêmica no Brasil.

Outra questão a ser considerada é que a WoS comporta apenas article, proceedings paper, review, book review e editorial, ou seja, dissertações e teses não constituem seu aporte. Além disso, apesar de abranger um vasto repertório, a WoS não inclui várias revistas de Educação Física de línguas que não são anglo-saxônicas, por isso os achados não compreendem a totalidade das produções brasileiras.

A Tabela 3 mostra os enfoques que mais têm chamado atenção dos pesquisadores, propiciando uma visão sobre os diversos nichos explorados no contexto "Educação Física e Mídia". Elas foram elencadas de modo decrescente, ficando explícito que a consciência em relação ao poder de influência da mídia sobre a formação de subjetividades do público é a ideia mais compartilhada nos estudos. A categoria que concentra essa noção aparece no topo, como mais recorrente. As demais permitem observar que, mesmo com o decréscimo numérico, o uso da mídia como recurso didático, objeto de análise, meio para coletar dados e fator que impacta no nível de atividade física seguem de maneira expressiva. Daí por diante, o declínio em relação à quantidade se acentua, vindo à tona os assuntos menos explorados.

Outro fator a ser considerado diz respeito à interface com variadas áreas de conhecimento. Ficou nítido que, em se tratando da temática "Educação Física e Mídia”, as discussões tendem mais às interfaces das Ciências Humanas e Sociais, em comparação às Ciências da Saúde (Figura 8), onde a Educação Física está 
compreendida. Segundo Lüdorf e Castro, apesar de ela estar classificada na área 21, Saúde, ela é multidisciplinar por constituição. Neste contexto, as subáreas pedagógica e sociocultural valorizam fortemente o viés cultural dos fenômenos, por isso dialogam bastante com Sociologia, Filosofia, Educação, dentre outras.

Considerando os resultados obtidos com a Análise de Conteúdo, esta interlocução fica ainda mais transparente através da essência das categorias presentes na Tabela 3. Por meio delas observamos que, apesar da mídia ser tangenciada de forma mais expressiva como "agente influenciador da formação de subjetividades", diversas outras categorias apresentam ligação com a realidade escolar, como é o caso de "recurso didático", que aprece em segundo lugar e outras como: "recurso utilizado para desenvolvimento profissional"; "educação midiática"; "fonte de informação"; "meio para promover educação à distância"; "recurso utilizado para avaliar"; "fator a ser considerado na elaboração do currículo"; "fator que impacta o desempenho escolar"; "recurso para envolver pais no processo ensino-aprendizagem"; "recurso utilizado para gestão do ensino"; e "fator que impacta no desempenho motor". Chama atenção que, apesar das diferenças relacionadas aos procedimentos metodológicos, bem como da fonte de dados e do período de coleta, que ocorreu sete anos depois da pesquisa realizada por Santos et al. (2014), determinados resultados apresentam similaridades, principalmente ao considerarmos as categorias que apresentam relação com a Educação Física Escolar, que em ambos aparecem como a segunda mais expressiva.

Destacamos que até o ano de 2019, período limite da extração dos dados na WoS, a utilização da mídia para certos fins educacionais apresenta um percentual muito baixo em relação aos demais como expresso pela categorização, considerando: "fonte de informação"; "meio para promover educação à distância"; "recurso utilizado para avaliar"; "fator a ser considerado na elaboração do currículo"; "fator que impacta o desempenho escolar"; "recurso para envolver pais no processo ensino-aprendizagem"; "recurso utilizado para gestão do ensino"; e "fator que impacta no desempenho motor". No entanto, é possível que a partir de 2020 ocorra uma mudança nesta configuração, dada a realidade que vem se estabelecendo no ensino por conta das medidas de biossegurança associadas à Covid-19 e possivelmente à necessidade de se manter o distanciamento social por algum tempo, ainda que se intercale com a reabertura das atividades. Neste entremeio, é possível que o uso da mídia como "recurso utilizado para desenvolvimento profissional" se torne mais expressivo, já que diversas palestras e cursos dos mais variados assuntos passaram a ser oferecidos online.

Outra realidade que pode sofrer alterações é aquela representada na Figura 10, que mostra a rede de relacionamento sobre as formas que a mídia é tangenciada nos estudos. Nela algumas categorias aparecem isoladas, como é o caso de: "recurso utilizado para gestão do ensino", "fator a ser considerado na elaboração do currículo"; "fator que impacta no desempenho escolar"; e "recurso para envolver pais no processo de ensino-aprendizagem dos alunos". Com o advento da educação remota/distância é provável que neste momento a configuração seja outra, então estudos futuros poderiam se dedicar à questão partindo do ano de 2020. 
Observando o baixo índice de publicações envolvendo a Educação Física na interface com a mídia, ficam sugeridos grandes desafios a serem superados, conforme havia alertado Bianchi e Pires (2015). Deste modo reforçamos a emergência da temática, ficando sugerido que os desafios não se limitam à realidade brasileira, já que estamos nos referindo a publicações internacionais. Neste contexto, o diálogo entre as diferentes instituições em nível nacional e internacional seria valoroso, pois envolveria experiências provenientes de culturas e realidades diversas e por vezes discrepantes, considerando o desenvolvimento humano e o acesso às tecnologias.

Salientamos que, além do uso instrumental da mídia pela Educação Física, é preciso atentar para a necessidade de maior atenção sobre a perspectiva crítica, conforme aponta Belloni (2009). Em nossa categorização tal concepção está presente em "educação midiática". Sua essência está atrelada ao desenvolvimento da criticidade dos alunos acerca de discursos normativos presentes nos meios de comunicação, incluindo adesão de hábitos considerados saudáveis, questões de gênero, diversidade étnica, padrão corporal, consumo de produtos e serviços e temas ligados ao esporte. Para Foucault (1979), o corpo é um artefato indispensável ao exercício do poder, então é preciso que pesquisadores e educadores estejam atentos ao que é divulgado cotidianamente sobre ele.

Nesta direção ainda constatamos, por meio da Figura 10, que a categoria "fonte de informação" se liga apenas a "recurso didático", o que indica a abordagem da mídia para fins de pesquisa e obtenção de informação. O fato de "fonte de informação" não se ligar à "educação midiática" mostra que a mídia não tem sido objeto de crítica nos documentos investigados. Enfatizamos a importância desta ligação, já que há inúmeros digital influencers prestando aconselhamentos sobre o corpo sem ter formação, além de aplicativos digitais ligados à prescrição de treinamento físico. O mesmo raciocínio se aplica ao considerarmos "fator que impacta no nível de atividade física", pois em geral as produções midiáticas que requisitam este discurso reforçam o paradigma hegemônico da Educação Física. Trata-se daquele em que os aspectos biológicos do exercício físico são valorizados demasiadamente, desconsiderando a história coletiva e culpabilizando os indivíduos por supostos fracassos ligados à adesão da prática de exercícios físicos (PALMA, 2001).

Outros fatores que emergiram com a Análise de Conteúdo são: o uso de recursos da mídia como "meio para coleta de dados", em que destacamos o viés ligado à aplicação de instrumentos online como novidade; o uso da mídia para fins de "divulgação esportiva" e a mídia como um "fator que impacta na gestão esportiva", ambos com um percentual muito baixo de publicações (Tabela 3) e sem correlação com outros fatores (Figura 10), demonstrando que a Educação Física não tem se atentado muito a estas questões.

Como vimos, o presente estudo mapeou um recorte do conhecimento, aclarando diversos nichos que fazem ou fizeram parte da atenção dos pesquisadores. Neste contexto, ficaram evidentes aqueles que receberam maior e menor atenção, podendo ser útil como ponto de partida para futuras investigações ou mesmo como um despertar para temáticas relevantes. Além disso, considerando a aplicação das medidas de biossegurança relacionadas à Covid-19, bem como as drásticas 
mudanças impostas à rotina, que culminaram no cancelamento de muitas atividades presenciais e na tentativa de adaptação para o modo online, o panorama apresentado aqui é um modo de evidenciar as relações estabelecidas entre "Educação Física e mídia" no período que antecede estas transformações, que provavelmente gerarão novas configurações e que deverão ser foco de futuros estudos.

\section{REFERÊNCIAS}

AZEVEDO-FERREIRA, Maxwel; SANTOS-SOUZA, Humberto Reis, ALVES, Simone. O Perfil de Pesquisa do Instituto Federal de Educação, Ciência e Tecnologia do Rio de Janeiro (IFRJ): Campus Avançado Resende. In: CONGRESSO DE ADMINISTRAÇÃO, SOCIEDADE E INOVAÇÃO, 11, 2018, Rio de Janeiro. Anais [...]. Rio de Janeiro: ECEME, 2018, v. 11, p. 1-13. Disponível em: https://even3.blob.core.windows.net/anais/119241.pdf. Acesso em: 30 mar. 2020.

BARDIN, Laurence. Análise de conteúdo. São Paulo: Edições 70, 2011.

BELLONI, Maria Luiza. O que é mídia-educação. Campinas: Autores Associados, 2009.

BETTI, Mauro; PIRES, Giovani de Lorenzi. Mídia. In: GONZÁLEZ, Fernando Jaime; FENSTERSEIFER, Paulo Evaldo. Dicionário crítico de Educação Física. ljuí: Unijuí, 2005. p. 282-288.

BIANCHI, Paula; PIRES, Giovani de Lorenzi. Cultura digital e formação de professores de Educação Física: estudo de caso na Unipampa. Movimento, v. 21, n. 4, p. 1025-1036, ago. 2015. DOI:https://doi.org/10.22456/1982-8918.53778

CASADO, Elías Sanz; MORENO, Carmen Martín. Técnicas bibliométricas aplicadas a los estudios de usuarios. Revista General de Información y Documentación, v. 7, n. 2, p. 41, jan. 1997. Disponível em: https://www.researchgate.net/publication/39281534_Tecnicas bibliometricas_aplicadas_a_los_estudios_de_usuarios. Acesso em: 09 mar. 2020.

CHEN, Xiaotian. The declining value of subscription-based abstracting and indexing services in the new knowledge dissemination era. Serials Review, v. 36, n. 2, p. 79-85, jun. 2010. DOI https://doi.org/10.1080/00987913.2010.10765288.

DELATAS, Elvira Ruiz de Osma. Evaluación de la producción científica del área biomédica de la Universidad de Granada (1988-1996). 2003. 386 f. Tesis (Doctorado en Documentación) Departamento de Biblioteconomía y Documentación, Universidad de Granada, Granada, 2003. Disponível em: https://digibug.ugr.es/bitstream/ handle/10481/777/15755319.pdf? sequence=1\&isAllowed=y. Acesso em: 20 mar. 2020.

FOUCAULT, Michael. Microfísica do poder. Rio de Janeiro: Graal, 1979.

JOB, Ivone. Bibliometria aplicada aos estudos do campo da Educação Física: confiabilidade, qualidade e relevância nas publicações. Motrivivência, v. 30, n. 54, p. 18-34, jul. 2018. DOI https://doi.org/10.5007/2175-8042.2018v30n54p18.

LINS, Bernardo Felipe E. A evolução da Internet: uma perspectiva histórica. Cadernos ASLEGIS, v. 48, p. 11-45, abr. 2013. Disponível em: https://bit.ly/2T9VnXC. Acesso em: 23 nov. 2020. 
LUDORF, Silvia Maria Agatti; CASTRO, Pedro Henrique Zubcich Caiado. Realidades da pós-graduação em educação física: manutenção ou desmonte das subáreas sociocultural e pedagógica? In: TELLES, Silvio de Cássio Costa; LUDORF, Silvia; Pereira, Erik. Pesquisa em educação física: perspectivas sociocultural e pedagógica em foco. Rio de Janeiro: Autografia, 2017. p. 21-29.

MORENO-CEJA, Faustino. Producción científica de los investigadores de la Universidad de Guadalajara reportada en el ISI WEB OF KNOWLEDGE, durante el periodo 1996-2005: un análisis bibliométrico desde el modelo departamental. 2010. 299 f. Tese (Doctorado en Documentación: Archivos y Bibliotecas en el Entorno Digital) - Departamento de Biblioteconomía y Documentación, Universidad, Carlos III de Madrid, Getafe, 2010. Disponível em: https://e-archivo.uc3m.es/bitstream/handle/10016/7558/ Tesis\%20NOVIEMBRE\%2030.pdf?sequence=1\&isAllowed=y. Acesso em: 20 mar.2020.

PALMA, Alexandre. Educação Física, corpo e saúde: uma reflexão sobre outros "modos de olhar". Revista Brasileira de Ciências do Esporte, v. 22, n. 2, p. 23-39, jan. 2001. Disponível em: http://www.revista.cbce.org.br/index.php/RBCE/article/viewFile/410/384. Acesso em: 22 abr. 2020.

SÁNCHEZ, María Luisa Lascurain. Análisis de la actividad científica y del consumo de información de los psicólogos españoles del ámbito universitario durante el período 1986-1995. 2001. 304 f. Tese (Doctorado en Documentación: Archivos y Bibliotecas en el Entorno Digital)- Departamento de Biblioteconomía y Documentación, Universidad, Carlos III de Madrid, Madrid, 2001. Disponível em: https://e-archivo.uc3m.es/handle/10016/498. Acesso em 20 mar. 2020.

SANCHO, Rosa. Indicadores bibliométricos utilizados en la evaluación de la ciencia y la tecnología: revisión bibliográfica. Revista española de documentación científica, v. 13, n. 3/4, p. 842-865, 1990. DOI http://hdl.handle.net/10261/23694.

SANTOS, Silvan Menezes; BRUGGEMANN, Ângelo Luiz; POFFO, Bianca Natália; SILVEIRA, Juliano; BIANCHI, Paula; CRUZ JUNIOR, Gilson; FAUTH, Fernanda. Estudo da produção científica sobre Educação Física e mídia/TICS em periódicos nacionais (20062012). Revista Brasileira de Ciências do Esporte, v. 36, n. 2, p. S123-S139, abr./jun. 2014. Disponível em: http://revista.cbce.org.br/index.php/RBCE/article/view/2122/1080. Acesso em: 20 jan. 2019.

ZABALA, Antoni. A prática educativa: como ensinar. Porto Alegre: ArtMed, 1998. 
Abstract: We mapped studies that involve relationships between 'Physical Education and the media' and identified how the media is touched by Physical Education, reflecting on the findings. The methodological procedures include bibliometrics analyses carried out on Web of Science for 1945-2019, and Content Analysis. The theme is emerging and has not been addressed globally. Brazilian participation is highlighted, but the total number of publications is low. The areas of knowledge that most discuss the subject are the Humanities, Health Sciences and Applied Social Sciences. There are challenges to be overcome regarding collaboration networks among authors, institutions and countries. Prominent categories include 'influence of the media to form the audience's subjectivities' and those that, based on different specificities, are linked to the school.

Keywords: Physical Education. Media. Bibliometry

Resumen: Mapeamos estudios a respecto de relaciones entre "Educación Física y medios de comunicación" e identificamos cómo roza la Educación Física a los medios de comunicación. Los procedimientos metodológicos incluyen Bibliometría realizada en la Web of Science en el periodo comprendido entre 1945 y 2019 y Análisis de Contenido. Se trata de un tema emergente que no ha sido abordado a nivel mundial. Hay destaque en la participación brasileña, pero el número total de publicaciones es bajo. Las áreas de conocimiento que más discuten este tema son las Ciencias Humanas, Ciencias de la Salud y Ciencias Sociales Aplicadas. Hay retos a superar en relación a las redes de colaboración entre autores, instituciones y países. Las categorías destacadas incluyen "influencia de los medios de comunicación en la formación de subjetividades del público" y aquellas que, en base a diferentes especificidades, se vinculan a la escuela.

Palabras clave: Educación Física. Medios de comunicación. Bibliometría. 


\section{LICENÇA DE USO}

Este um artigo publicado em Open Access sob a licença Creative Commons Attribution 4.0 International (CC BY 4.0), que permite seu uso, distribuiçao e reproduçao em qualquer meio, sempre que se cite corretamente a obra original. Mais informação em: http://creativecommons.org/licenses/by/4.0

\section{CONFLITO DE INTERESSES}

Os autores declararam que não existe nenhum conflito de interesses neste trabalho.

\section{CONTRIBUIÇÕES AUTORAIS}

Cássia Marques Cândido: contribuiu para a realização de todas as etapas do estudo, desde sua idealização, execução e preparação do texto final.

Maxwel de Azevedo Ferreira: contribuiu para a realização de todas as etapas do estudo, sobretudo no processo de coleta e tratamento dos dados quantitativos.

Alexandre Palma de Oliveira: contribuiu para a realização de todas as etapas do estudo, desde sua idealização, execução e preparação do texto final.

Monique Ribeiro de Assis: Contribuiu para a realização de todas as etapas do estudo, como professora orientadora.

\section{FINANCIAMENTO}

Este trabalho não contou com apoio de nenhum órgão financiador.

\section{COMO REFERENCIAR}

CÂNDIDO, Cássia Marques; AZEVEDO-FERREIRA, Maxwel; OLIVEIRA, Alexandre Palma de; ASSIS, Monique Ribeiro de. Educação Física e mídia: estudo bibliométrico na Web of Science de 1945-2019. Movimento (Porto Alegre), v.27, p. e27024, jan. / dez. 2021. Disponível em: https://seer.ufrgs.br/Movimento/ article/view/102377. Acesso em: [dia] [mês abreviado]. [ano]. DOI: https://doi. org/10.22456/1982-8918.102377

\section{RESPONSABILIDADE EDITORIAL}

Alex Branco Fraga*, Elisandro Schultz Wittizorecki*, Ivone Job*, Mauro Myskiw*, Raquel da Silveira*

*Universidade Federal de Rio Grande do Sul, Escola de Educação Física, Fisioterapia e Dança, Porto Alegre, RS, Brasil 